\title{
The Clinical Link and Therapeutic Impacts of Adequate High Vitamin D Supplementation among Children with Recurrent Urinary Tract Infection in Kurdistan Region/Iraq: A Case-Control Study
}

\section{Qazaryan $\mathrm{KSY}^{1 *}$, Akash $\mathrm{NSY}^{2}$, Zebari $\mathrm{HS}^{3}$ and Salih QM${ }^{4}$}

${ }^{1}$ Department of Pediatrics, Zakho General Hospital, Iraq

${ }^{2}$ Department of Oral Health and Hygiene, Baghdad Al-Yarmouk University, Iraq

${ }^{3}$ Department of Urology, University of Zakho, Iraq

${ }^{4}$ Department of Pediatrics Surgery, University of Duhok, Iraq

\section{Research Article}

Volume 5 Issue 1

Received Date: February 04, 2020

Published Date: February 21, 2020

DOI: 10.23880 /oajun-16000172

*Corresponding author: Khajik Sirob Yaqob Qazaryan, Specialist pediatrician, Department of pediatrics, Zakho General Hospital, Iraq, Tel: 96475048061; Email: khajikyaqob@yahoo.com

\section{Abstract}

Purpose: The goal of our research study is to prove that Vit D supplementation on children with frequent UTI has clinical effective role in the treatment and pathogenesis of the disease and that Vit D and UTI are strongly clinically linked.

Methods: This is case-control research study, 130 children aged 0-18 y with recurrent UTI were involved (case group) and compared with 130 children (control group) considering serum Vit D level measurement and following up participants for 9 months. ELISA (enzyme-linked immunosorbent assay) was used to measure serum Vit D level. The results data were analyzed to compare between both case and control groups.

Results: In our study and among 130 children aged 0-18 y with recurrent UTI (case group), 35 (27\%) were boys and 95 (73\%) were girls, and in healthy participants (control group) 42 (32\%) were boys and 88 (68\%) were girls consequently. The mean serum Vit D level in the case group before starting this research study was $(8 \mathrm{ng} / \mathrm{ml})$ in $62 \%$ and the incidence of frequent UTI was more than 10 times/month in 79\%; after administration of 1000-5000 IU of Vit D, a remarkable raise of Vit D (22ngml) in $59 \%$ with decline incidence and frequency (less than 3 times/month) of UTI has been reported in $74 \%$.

Conclusion: In our case-control study, based on our results and data, we reported that Vit D supplementation in children with frequent UTI has very good clinical effective role in the treatment and elimination of the incidence of UTI in such cases. Adequate relatively high effective dose of Vit D (1000 IU-5000 IU) must be administered in children with UTI according to age and severity, this supplementation has very significant key role to decline the incidence, frequency as well as the common clinical symptoms and signs of UTI in children aged 0-18 y.

Keywords: Children aged 0-18y; Vit D adequate dose; Recurrent UTI 


\section{Open Access Journal of Urology \& Nephrology}

Abbreviations: ELISA: Enzyme-Linked Immunosorbent Assay; UTI: Urinary Tract Infection; NRC: Nutrition Rehabilitation Center; VCUG: Voiding Cystourethrogram.

\section{Introduction}

In pediatrics age group, infection of the urinary tract (UTI) is not uncommon. It is more noticeable clinically in girls (5.3\%) than in boys (1\%). Recurrent UTI is defined and diagnosed in children if they have possessed the following criteria:

- 2 or more episodes of UTI with acute pyelonephritis/ upper UTI or

- 1 episode of UTI with acute pyelonephritis plus 1 or more episode of UTI with cystitis/lower UTI or

- 3 or more episodes of UTI with cystitis/lower UTI [1].

Although three categories of such disease occur in children in forms of cystitis, acute pyelonephritis, and a symptomatic bacteriuria. Acute pyelonephritis is the most dangerous, risky and threatening form of urinary tract infection in children. In $90 \%$ of the clinically confirmed UTI cases in pediatrics age group, Escherichia coli is the most common, frequent and causative pathogen [2-4]. Chronic renal failure, hypertension and renal scarring as a result of late diagnosis of UTI might occur, hence early diagnosis and treatment of UTI is compulsory [5-8]. In children, the most frequent predisposing risk factor for UTI is vesicoureteral reflux [9]. The role of vitamin D in recurrent UTI in children is still unclear and contradictory due to limited researches in this field [10-12]. However, few think that vitamin D can reduce UTI in children, whereas, others such as Katikaneni, et al. [12] believes that vitamin D supplementation is a risky contributing factor for UTI in children.

On the other hand, vitamin D has lots of extra skeletal properties and advantages, in addition to hemostases and calcium phosphate metabolism, such as antibacterial effects and immunmodulatory benefits [13-16]. Certain studies are conducted to illustrate the positive clinical role of vitamin D in some contagious disease such as tuberculosis, upper and lower respiratory tract infection in children and adults [1719]. In this study we focus on the risk factors contributing to UTI in children and the beneficial role of vitamin D in the treatment of recurrent UTI in pediatrics age group.

\section{Materials and Methods}

\section{Study design}

In this case-control study, 130 children with frequent recurrent UTI as a case group were compared to 130 healthy children (control group) in terms of serum vitamin D level measurement. This study was conducted in Zakho General
Hospital, department of pediatrics and pediatrics private clinic with the inclusion of nutrition rehabilitation center (NRC) in Zakho district in Kurdistan region/Iraq. The age of the participants was between 0-18 y old. In new born baby and young age case group, certain criteria was included, in particular, frequent recurrent UTI, persistence of clinical symptoms such as hyperpyrexia, irritability, excessive crying and colic, anal fissure, poor feeding and appetite, vomiting, oral thrush particularly in girls, bad urine odor, discoloration of the napkins, abnormal urethral discharge, low birth weight, delayed growth, pus in the urine (pyuria), while in infants and older children, abdominal pain, malaise, dysuria, frequency, nocturnal enuresis, poor appetite, underweight, delayed growth, picky eaters with poor growth, bad oral smell, dental carries and gums inflammation, positive urine culture as well as lack of VU reflux, labial adhesions, urethral stricture, neurogenic bladder, circumcision in boys, hydronephrosis and posterior urethral valve. Participants with one attack of UTI, received antimicrobial prior admission, confirmed risk factors and well known underlying illness were excluded from this research study. Moreover, colic in infancy due to anal fissure was excluded. Besides, children with malnutrition and un healthy eating were excluded as well from this research study.

In our study, we did apply group matching for those visiting zakho general hospitals to select five hundred healthy children (control group) among those children who were visiting our hospital for vaccination or elective surgeries such as tonsillectomy with frequent organized sampling to reach the desired needed sample size. Certain factors were considered when matching the case and control groups including gender, age, weight, height, head circumference, nutrition status, breast feeding, socioeconomic status, family size and monthly income $[20,21]$. Both included cohorts were from Zakho, villages around, Mosel, Zomar and Shengal and children had received vaccination and under control and assessment of health centers with administration of vitamin D regularly till age of three years.

Urinary system abnormalities and VU reflux were figured out using diagnostic ultrasongraghy and voiding cystourethrogram (VCUG). The pediatric surgeon and via clinical examination ruled out labial adhesions, picky eaters, un healthy children, anal fissure, posterior urethral valve and congenital renal malformation. We obtained written consent forms from the parents and verbal agreements from older children after introducing our approved research plan to them. Then, blood sample (3cc) was taken from participants for vitamin D level measurement. Centrifugation of isolated serum samples less than 20 degree centigrade was achieved using ELISA method. Tests were completed and performed in Zakho General Hospital labs and private labs in Zakho District-Kurdistan region/Iraq. We divided the included 


\section{Open Access Journal of Urology \& Nephrology}

children, in this research study, into five categories according to serum vitamin D levels: very severe $<5 \mathrm{ng} / \mathrm{ml}$, severe $5-10 \mathrm{ng} / \mathrm{ml}$, vitamin D deficiency $10-20 \mathrm{ng} / \mathrm{ml}$, < sufficient level 20-30, and $>30$ sufficient vitamin D level [22]. We use presentation tables and numeric indicators to demonstrate and clarify the results obtained in this control-case study.

Furthermore, children received every day 1000 IU-5000 IU Vit D supplementation as drops or tab to case group, and placebo for control group for 9 months. Children in both cohorts were monitored and observed under unique follow up for the administration of Vit D and for the clinical signs of UTI and addressed accordingly.

\section{Ethics Statement}

Details and information about the research study were given and illustrated for parents and they signed consent forms to include their children in this study were with ethics approval of the research department in Zakho General Hospital.

\section{Results}

One hundred and thirty children with recurrent UTI were involved in this research study, among them case group, 35 were boys (27\%) and 95 were girls (73\%). In control group healthy children, 42 were boys (32\%) and 88 were girls (68\%), respectively. Our results illustrated that there was no important variation among the two cohorts (case and control groups) in terms of gender, age, weight, height, head circumference and exclusive breast feeding duration (Table 1). In the case group, the lowest and highest serum vitamin D levels were 8 and $12 \mathrm{ng} / \mathrm{ml}$, respectively, whereas in the control cohort, the lowest and highest serum vitamin D levels were 16 and $22 \mathrm{ng} / \mathrm{ml}$, respectively. In terms of serum vitamin $\mathrm{D}$ level, there was an outstanding variation between the control and case cohorts in our study with significant variables in severity of vitamin D deficiency (Table 2). Very significant decline in the incidence of UTI in both groups were observed with important increase in Vit D as illustrated in Table 3.

\begin{tabular}{|c|c|c|}
\hline Characteristics & Case group (\%) & Control group (\%) \\
\hline Number & $130(100 \%)$ & $130(100 \%)$ \\
\hline Age (months) & $55+-32.5$ & $63+-34.2$ \\
\hline Sex (boys: girls) & 0.335416667 & 0.507638889 \\
\hline Weight (kg) & $14+-6.4$ & $16+-9.1$ \\
\hline Height (cm) & $97.2+-21.4$ & $411.3+-21.4$ \\
\hline Head circumference (cm) & $44+-2.3$ & $44+-3$ \\
\hline Family history of congenital renal disease & None & None \\
\hline
\end{tabular}

Values are presented as number, mean+-SD and median

Table 1: Number and percentage characteristics of children in both case and control cohorts.

\begin{tabular}{|c|c|c|}
\hline Serum vitamin D level (ng/ml) & Case group & Control group \\
\hline Very low (5-10ng/ml) & $15(13 \%)$ & $22(17 \%)$ \\
\hline Low (10-20ng/ml) & $52(40 \%)$ & $56(43 \%)$ \\
\hline Insufficient (20-30ng/ml) & $43(33 \%)$ & $49(38 \%)$ \\
\hline Total & $130(100 \%)$ & $130(100 \%)$ \\
\hline
\end{tabular}

Values are presented as number (\%)

Table 2: Categories of serum vitamin D level among participants case and control groups.

\begin{tabular}{|c|c|c|c|c|}
\hline \multirow{2}{*}{ Variables } & \multicolumn{2}{|c|}{ Time of Vit D supplementation } & \multirow{2}{*}{$\begin{array}{c}\text { Case group } \\
\text { (130) }\end{array}$} & \multirow{2}{*}{$\begin{array}{c}\text { Control group } \\
\text { (130) }\end{array}$} \\
\hline & Before this study & After this study & & \\
\hline Vitamin D (ng/ml) mean level & 8 & 22 & $78(60 \%)$ & $82(63 \%)$ \\
\hline Incidence and Frequency of UTI & $\begin{array}{l}\text { Equal or more than } 10 \\
\text { times/month }\end{array}$ & $\begin{array}{c}\text { Less than } 3 \text { times/ } \\
\text { month }\end{array}$ & $97(74 \%)$ & $92(71 \%)$ \\
\hline
\end{tabular}

Table 3: Frequency of UTI in both case and control groups before and after vitamin D supplementation. 


\section{Open Access Journal of Urology \& Nephrology}

Based on urine culture and sensitivity and in both groups, E.coli was the most relevant and frequent pathogen in children with recurrent UTI. Furthermore, in infants the most common clinical features were poor feeding, colic and excessive crying, oral thrush mainly in girls, while in older children fever, vomiting, abdominal and loin pain, frequency and burning micturition, loss of appetite and poor growth were the most commonest features. A remarkable and tremendous decline of the common clinical symptoms and signs of UTI in both groups was reported in our study as shown in Table 4.

\begin{tabular}{|c|c|c|}
\hline \multirow{2}{*}{ Age } & \multicolumn{2}{|c|}{ Common clinical symptoms and signs in both cohorts in percentages (\%) } \\
\cline { 2 - 3 } Less than 1 year & Before Vit D supplement & After Vit D supplement \\
\hline More than 1 year & $\begin{array}{c}\text { Fever (42\%), poor feeding (53\%), Colic and } \\
\text { excessive crying (88\%), Oral thrush (65\%), Anal } \\
\text { fissure (72\%) }\end{array}$ & $\begin{array}{c}\text { Fever (22\%), poor feeding (13\%), Colic and } \\
\text { excessive crying (8\%), Oral thrush (5\%), Anal } \\
\text { fissure (2\%) }\end{array}$ \\
\hline $\begin{array}{c}\text { Fever (12\%), Vomiting (32\%), Abdominal pain } \\
\text { (75\%), Loin pain (76\%), Frequency (82\%), Dys- } \\
\text { uria (63\%), Poor appetite (77\%) }\end{array}$ & $\begin{array}{c}\text { Fever (2\%), Vomiting (2\%), Abdominal pain } \\
(5 \%), \text { Loin pain (6\%), Frequency (8\%), Dysuria } \\
\text { (6\%), Poor appetite (13\%) }\end{array}$ \\
\hline
\end{tabular}

Table 4: Common clinical symptoms and signs among case and control groups before and after Vit D supplementation.

\section{Discussion}

Right now, there are limited research studies confirming the positive impacts of Vitamin D level on pediatrics age groups based on clinical trials. However, in this case-control research study, results revealed that the use of therapeutic dose (1000-5000 IU) of vitamin D has very good clinical impacts on children with recurrent UTI. Previous studies have shown that children with frequent UTI had significant low vitamin D level which might increase the severity of their infection [23]. Accordingly, two schools are available to explain this matter, the 1 st school agree that Vit D supplementation is helpful and can improve frequent and recurrent UTI in children, the 2nd school disagree with the 1st opinion and concluded that Vit D increase the frequency of UTI in children. However, a study conducted on ninety three children with frequent UTI, suggested that their UTI was strongly linked to lower Vit D level in case group as compared to control group, and Vit D is a risky factor in children with recurrent UTI [23,24].

A remarkable correlation between incidence of UTI and urine cathelicidin (LL-37) level have been addressed according to certain studies [24]. The mechanism beyond this is that Vit D has anti-bacterial and anti-inflammatory key role in the pathogenesis and incidence of UTI in children through production of peptides known as cathelicidin and modulate, $\beta$-defensin to produce cytokines and decrease the inflammatory process [25]. Another study conducted by Tekin, et al. [26] and Yang, et al. [10] on eighty tow children aged 2-18 y with 1st UTI, concluded that Vit D is a risk factor for UTI in children.

In our study, the common clinical symptoms and signs of UTI in both case and control groups were significantly declined as declared in Table 4 . The most common clinical features of UTI in children under 1 year prior to commencing with Vit D supplement were as follows: Fever (42\%), poor feeding (53\%), Colic and excessive crying (88\%), Oral thrush (65\%), and Anal fissure (72\%) whereas, in the same age group the same clinical features had great decline after Vit D supplement as follows: Fever (22\%), poor feeding (13\%), Colic and excessive crying (8\%), Oral thrush (5\%), Anal fissure (2\%). Similarly, for children more than 1 year before administration with Vit D, the common symptoms were Fever (12\%), Vomiting (32\%), Abdominal pain (75\%), Loin pain $(76 \%)$, Frequency (82\%), Dysuria (63\%), Poor appetite (77\%); and the same group had great improvement after Vit D supplementation who presented clinically as Fever (2\%), Vomiting (2\%), Abdominal pain (5\%), Loin pain (6\%), Frequency (8\%), Dysuria (6\%), Poor appetite (13\%).

Moreover, a case-control study on thirty six children reported that children with recurrent UTI have low urine cathelicidin level, hence those children with UTI and Vit D deficiency are not able to increase their urine cathelicidin level [27]. Therefore, children with sufficient Vit D during UTI can produce enough cathelicidin to act as antibacterial and anti-inflammatory marker during UTI [27]. In addition, cathelicidin maintain healthy urinary system via producing cytokines and chemokines by various cells, and macrophages infected with bacterial pathogens are in active to make enough peptides [28-33]. Therefore, in adequate production of antibacterial peptides can predispose to UTI and increase the severity of infection in children with low Vit D [34,35].

In addition, as we mentioned already, the 2nd school concerning the link between Vit D and UTI in children has opposite views based on certain studies. For instance, in a research study conducted on three hundred and fifteen 


\section{Open Access Journal of Urology \& Nephrology}

infants with formula fed feeding, the study reported that vitamin D increase the incidence and severity of UTI and supplementation of Vit D must be done cautiously [36]. To explain this, certain reasons were addressed and believed on how does Vit D administration can be a predisposing factor and might increase UTI in children. Firstly, as a result of overdose of Vit D supplementation, nephrocalcinosis as a core of bacterial growth can be created and increase the severity of infection [37]. Secondly, Vit D administration might suppress the immune system via production of $25(\mathrm{OH}) \mathrm{D}$ which act as immune modulator, and when there is infection modification of 25(OH) D to 1, 25-dihydroxy occurs on infection site resulting in sever prolonged UTI [38]. Also, administration of Vit D can lead to irregular and hyperactive immune system to infection through 25(OH)D overload which acts as antagonist to 1,25-dihydroxy vitamin D at vitamin D receptor $[39,40]$. In our study, we reported that children with recurrent UTI showed clinical improvement in their symptoms and signs after they were given adequate Vit D (1000-5000 IU) supplementation regularly for 9 months.

\section{Conclusion}

In our case-control study, based on our results and data we reported that Vit D supplementation in children with frequent UTI has very good clinical effective role in the treatment and elimination of the incidence of UTI in such cases. Adequate daily effective dose of Vit D (1000 IU-5000 IU) must be administered in children with UTI according to age and severity of UTI to decrease the usual clinical symptoms and signs among children with low Vit D level in their blood. More studies are needed to support this study including larger sample size, various age groups, different place and environment with modification of Vit D supplementation.

\section{Acknowledgment}

Our best gratitude and thanks to the parents and children who gave their agreement to share in this research study. Many thanks to the department of pediatrics, Nutrition Rehabilitation Center (NRC) in Zakho General Hospital in Kurdistan/Iraq for their kind support.

\section{References}

1. National Institution for Health and Care Excellence (2018) Urinary tract infection (recurrent): antimicrobial prescribing.

2. Elder JS (2016) Urinary tract infections. In: Kliegman RM, et al. (Eds.), Nelson textbook of pediatrics. $20^{\text {th }}$ (Edn.), Philadelphia (PA): Elsevier Saunders, pp: 25542563.
3. Bensman A, Dunand O, Ulinski T (2009) Urinary tract infection. In: Avner ED, et al. (Eds.), Pediatric nephrology. $6^{\text {th }}$ (Edn.), Berlin: Springer, pp: 1007-1025.

4. Wald ER (2009) Cystitis and pyelonephritis. In: Feigin RD, et al. (Eds.), Feigin and Cherry's text book of infectious diseases. ${ }^{\text {th }}$ (Edn.), Philadelphia (PA): Elsevier Saunders, pp: 554-569.

5. Ayazi P, Mahyar A, Daneshi MM, Jahani Hashemi H, Pirouzi M, et al. (2009) Comparison of procalcitonin and C-reactive protein tests in children with urinary tract infection. Iran J Pediatr 19(4): 381-386.

6. Ayazi P, Moshiri SA, Mahyar A, Moradi M (2011) The effect of vitamin A on renal damage following acute pyelonephritis in children. Eur J Pediatr 170(3): 347350.

7. Stokland E, Hellström M, Jacobsson B, Jodal U, Sixt R (1996) Renal damage one year after first urinary tract infection: role of dimercaptosuccinic acid scintigraphy. J Pediatr 129(6): 815-820.

8. Rushton HG (1997) Urinary tract infections in children. Epidemiology, evaluation, and management. Pediatr Clin North Am 44(5): 1133-1169.

9. Leonardo CR, Filgueiras MF, Vasconcelos MM, Vasconcelos $\mathrm{R}$, Marino VP, et al. (2007) Risk factors for renal scarring in children and adolescents with lower urinary tract dysfunction. Pediatr Nephrol 22(11): 1891-1896.

10. Yang J, Chen G, Wang D, Chen M, Xing C, et al. (2016) Low serum 25-hydroxyvitamin D level and risk of urinary tract infection in infants. Medicine (Baltimore) 95(27): 4137.

11. Jorde R, Sollid ST, Svartberg J, Joakimsen RM, Grimnes G, et al. (2016) Prevention of urinary tract infections with vitamin D supplementation 20,000IU per week for five years. Results from an RCT including 511 subjects. Infect Dis (Lond) 48(11-12): 823-828.

12. Katikaneni R, Ponnapakkam T, Ponnapakkam A, Gensure $R$ (2009) Breastfeeding does not protect against urinary tract infection in the first 3 months of life, but vitamin D supplementation increases the risk by $76 \%$. Clin Pediatr 48(7): 750-755.

13. Guillot $\mathrm{X}$, Semerano L, Saidenberg-Kermanac'h N, Falgarone G, Boissier MC (2010) Vitamin D and inflammation. Joint Bone Spine 77(6): 552-557.

14. Holick MF (2010) Vitamin D: extraskeletal health. Endocrinol Metab Clin North Am 39(2): 381-400. 


\section{Open Access Journal of Urology \& Nephrology}

15. Lagishetty V, Liu NQ, Hewison M (2011) Vitamin D metabolism and innate immunity. Mol Cell Endocrinol 347(1-2): 97-105.

16. Hewison M (2011) Antibacterial effects of vitamin D. Nat Rev Endocrinol 7(6): 337-345.

17. Wilkinson RJ, Llewelyn M, Toossi Z, Patel P, Pasvol G, et al. (2000) Influence of vitamin D deficiency and vitamin D receptor polymorphisms on tuberculosis among Gujarati Asians in west London: a case-control study. Lancet 355(9204): 618-621.

18. Muhe L, Lulseged S, Mason KE, Simoes EA (1997) Casecontrol study of the role of nutritional rickets in the risk of developing pneumonia in Ethiopian children. Lancet 349(9068): 1801-1804.

19. Laaksi I, Ruohola JP, Tuohimaa P, Auvinen A, Haataja $R$, et al. (2007) An association of serum vitamin D concentrations $<40 \mathrm{nmol} / \mathrm{L}$ with acute respiratory tract infection in young Finnish men. Am J Clin Nutr 86(3): 714-717.

20. McNally JD, Leis K, Matheson LA, Karuananyake C, Sankaran K, et al. (2009) Vitamin D deficiency in young children with severe acute lower respiratory infection. Pediatr Pulmonol 44(10): 981-988.

21. Schluter P, Carter S, Kokaua J (2007) Indices and perception of crowding in Pacific households domicile within Auckland, New Zealand: findings from the Pacific Islands Families Study. N Z Med J 120(1248): 2393.

22. Holick MF (2007) Vitamin D deficiency. N Engl J Med 357(3): 266-281.

23. Nseir W, Taha M, Nemarny H, Mograbi J (2013) The association between serum levels of vitamin D and recurrent urinary tract infections in premenopausal women. Int J Infect Dis 17(12): 1121-1124.

24. Nielsen KL, Dynesen P, Larsen P, Jakobsen L, Andersen PS, et al. (2014) Role of urinary cathelicidin LL-37 and human $\beta$-defensin 1 in uncomplicated Escherichia coli urinary tract infections. Infect Immun 82 (4): 1572-1578.

25. Kwon YE, Kim H, Oh HJ, Park JT, Han SH, et al. (2015) Vitamin D deficiency is an independent risk factor for urinary tract infections after renal transplants. Medicine (Baltimore) 94(9): 594.

26. Tekin M, Konca C, Celik V, Almis H, Kahramaner Z, et al. (2015) the association between vitamin D levels and urinary tract infection in children. Horm Res Paediatr 83(3): 198-203.
27. Övünç Hacıhamdioğlu D, Altun D, Hacıhamdioğlu B, Çekmez F, Aydemir G, et al. (2016) The association between serum 25-hydroxy vitamin D level and urine cathelicidin in children with a urinary tract infection. J Clin Res Pediatr Endocrinol 8(3): 325-329.

28. Liu PT, Stenger S, Li H, Wenzel L, Tan BH, et al. (2006) Toll-like receptor triggering of a vitamin D-mediated human antimicrobial response. Science 311(5768): 1770-1773.

29. Wang TT, Nestel FP, Bourdeau V, Nagai Y, Wang Q, et al. (2004) Cutting edge: 1,25-dihydroxyvitamin D3 is a direct inducer of antimicrobial peptide gene expression. J Immunol 173(5): 2909-2912.

30. Cantorna MT, Yu S, Bruce D (2008) The paradoxical effects of vitamin D on type 1 mediated immunity. Mol Aspects Med 29(6): 369-375.

31. White JH (2010) Vitamin D as an inducer of cathelicidin antimicrobial peptide expression: past, present and future. J Steroid Biochem Mol Biol 121(1-2): 234-238.

32. Chromek M, Slamová Z, Bergman P, Kovács L, Podracká $\mathrm{L}$, et al. (2006) The antimicrobial peptide cathelicidin protects the urinary tract against invasive bacterial infection. Nat Med 12(6): 636-641.

33. Lai Y, Gallo RL (2009) AMPed up immunity: how antimicrobial peptides have multiple roles in immune defense. Trends Immunol 30(3): 131-141.

34. Zasloff M (2007) Antimicrobial peptides, innate immunity, and the normally sterile urinary tract. J Am Soc Nephrol 18(11): 2810-2816.

35. White JH (2008) Vitamin D signaling, infectious diseases, and regulation of innate immunity. Infect Immun 76(9): 3837-3843.

36. Deluca HF, Cantorna MT (2001) Vitamin D: its role and uses in immunology. FASEB J 15(14): 2579-2585.

37. Yaqob S Khajik (2017) "Colic and Anal Fissure in Infancy": The Missing Significant Correlation. Ec pediatrics 4(3): 65-69.

38. Qazaryan KSY (2019) The clinical link of preschoolers' picky eating behavior with their growth, development, nutritional status, and physical activity in Iraq/Kurdistan region. Neurol Neurosci Rep 2.

39. Yaqob K (2019) P512 Children and healthy eating how do they understand it. Archives of Disease in Childhood 104(Suppl 3): 358. 


\section{Open Access Journal of Urology \& Nephrology}

40. Anand N, Chandrasekaran SC, Rajput NS (2013) Vitamin

Periodontol 17(3): 302-308.

$\mathrm{D}$ and periodontal health: Current concepts. J Indian Soc

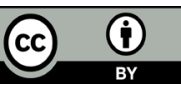

